\section{Cold War, Deadly Fevers: Malaria Eradication in Mexico, 1955-1975}

\section{Marcos Cueto, editor}

\section{Woodrow Wilson Center Press, Johns Hopkins University Press, Baltimore, Maryland, USA, 2007 ISBN: 978-0-8018-8645-4 Pages: 288; Price: US $\$ 45.00$}

Marcos Cueto is a medical historian who describes the details of malaria eradication efforts in Mexico in the context of the Cold War era authoritarianism. His approach works overall, but occasionally he overreaches.

Mr. Cueto asserts that the politics of the time allowed the medical community to be similarly authoritarian in forcing malaria eradication to be the accepted strategy. He states that the political climate relied on fear-based tactics of spreading anxiety about the communist threat and that similar strategies were used to gain public support for the malaria eradication effort, incorporating military jargon such as "enemy" mosquitoes and "campaigns" against disease into the public health lexicon. These campaigns included a propaganda arm in which pop stars became champions for the cause, to make the public sympathetic to their efforts. At one point, the author likens the strategy of screening persons for asymptomatic malaria parasitemia to the 1950s McCarthy-style witch hunts for hidden communists - stretching the analogy beyond tolerable limits.

A recurring theme in the book is Mr. Cueto's skepticism of new technologies, especially those introduced by other (non-Mexican) national or international organizations. He disparages the adoption of chloroquine, DDT, and smear microscopy as "magic bullet" strategies, claiming they distracted from rather than enhanced control efforts. He suggests that current efforts, which tout the use of long-last- ing insecticide-treated bed nets and artemisinin-based combination therapy, are similarly flawed. He never really articulates proven alternatives to the adoption of new technologies, but he vaguely suggests relying on community-based broad public health programs at the grassroots level.

I found the tone of the book a bit cynical and fatalistic. I got the impression that Mr. Cueto believes that all individuals and organizations attempting malaria eradication were doing so not for its own sake but rather as a front for other agendas such as centralizing national power in Mexico, furthering the international interests of capitalist countries, or personal glory. The author uses the fact that the eradication effort failed to support his contention that it was probably a bad idea in the first place.

Fast forward to today when there is a renewed interest in malaria control efforts. Witness the Global Fund to Fight AIDS, Tuberculosis, and Malaria; the Bill \& Melinda Gates Foundation; the President's Malaria Initiative; and pop stars such as Bono championing the cause, including the possibility of eradication. Sounds familiar. In light of the current progress of malaria control efforts in Mexico, where most states are now malaria free and the total number of cases has been steadily decreasing, Mexico is well on its way to achieving those original eradication goals. Thus, whether you agree with the author's politics or not, if you are considering getting into the business of malaria eradication, you could benefit by reviewing this very detailed historical account of a malaria eradication effort that was unsuccessful.

\section{Paul Arguin*}

${ }^{*}$ Centers for Disease Control and Prevention, Atlanta, Georgia, USA

Address for correspondence: Paul Arguin, Centers for Disease Control and Prevention, 4770 Buford Highway NE, Mailstop F22, Atlanta, GA 30341, USA; email: parguin@cdc.gov
Parasites and Infectious

\section{Diseases: Discovery by Serendipity and Otherwise}

\section{Gerald Esch}

Cambridge University Press, Cambridge, United Kingdom, 2007 ISBN-10: 0521675391, ISBN-13: 978-0521675390

Pages: 366; Price US $\$ 45.00$

The author of this book retells several of the famous stories of discovery in the field of vector-borne and parasitic diseases through the eyes of some of the most prominent researchers working in this field today. But Esch does not stop there- he goes on to connect these early stories with more recent watershed contributions as recounted through a series of interviews he references throughout the course of the book. For example, he describes the discovery of the African sleeping sickness agent, Trypanosoma gambiense, and the contributions in the early 1900s by Dutton, Castellani, and Bruce. He then moves on to more recent discoveries regarding immunity, antigenic variation, and the role of variable surface glycoproteins. He describes the seminal studies that were performed in this area as recounted through interviews with prominent parasitologists Dick Seed and Keith Vickerman. Through this process, Esch weaves a tapestry of the new and old as it relates to the history of important tropical diseases such as African typanosomiasis, malaria, yellow fever, HIV/AIDS, hookworm, and schistosomiasis, which continue to plague humankind.

The book has a novel organization; the first 100 pages are devoted to a lengthy prologue in which the major content contributors, the disease experts Esch interviewed, are extensively quoted and even venerated, in a casual, entertaining, and well-deserving 
manner. Many who peruse this book will be pleasantly surprised by the colorful biographies of well-known parasitologists and vector-borne disease specialists, who some readers no doubt will know as friends, colleagues, collaborators, professors, or even former students.

As the title suggests, there is an effort to locate threads of serendipity woven through the historical tapestry of discovery. The conclusions that emerge unsurprisingly are that serendipity has played a much less important role than one might naively surmise and that the qualities of hard work, rock-solid persistence, a keen mind, and the fortitude to swim against the academic tide have paid generous dividends.

No doubt the attribution of specific recent hallmark contributions by key persons, many of whom are still active in the field today, will be met with some degree of controversy. Nevertheless, the book is interesting, educational, and enjoyable, a "must have" for every library of tropical medicine or medical history. Thumbs up to Esch.

\section{Ben Beard*}

${ }^{*}$ Centers for Disease Control and Prevention, Fort Collins, Colorado, USA

Address for correspondence: C. Ben Beard, Bacterial Diseases Branch, Division of VectorBorne Infectious Diseases, Centers for Disease Control and Prevention, 3150 Rampart Rd, Mailstop P02, Fort Collins, CO 80521, USA; email: cbeard@cdc.gov

\section{Tracking trends and analyzing new and reemerging c U C I U infectious disease issues around the world INFECTIOUS DISEASES A peer-reviewed journal published by the National Center for Infectious Diseases Vol. 4 No. 3, July-Sept 1998}

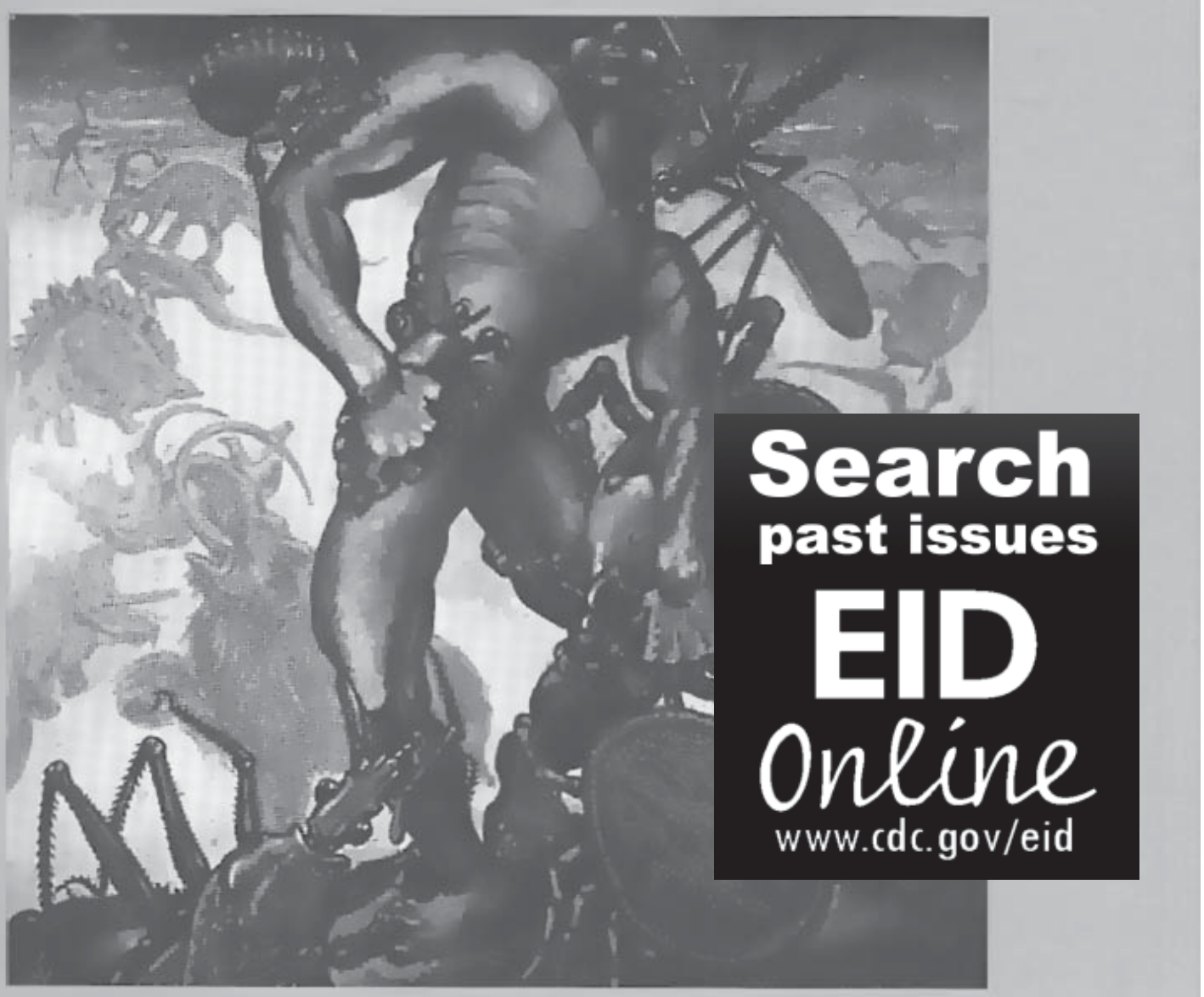

